\title{
The Effect Of Bipolar Radiofrequency Ablation (Novasure Endometrial Ablation System) on Endometrial Thickness and Bleeding in Patients with Premenopausal Bleeding \\ Ismael T. Elgarhy, Ashraf Hamdy, Sherif M. Elagamy \\ Department of Obstetrics and Gynecology, Faculty of Medicine-Al- Azhar University \\ Corresponding author: Sherif M. Elagamy; Mobile:01091133258; Email: mohamedgamalomr90@gmail.com
}

\begin{abstract}
Background: Ablation of the endometrial lining of the uterus as an alternative to hysterectomy was found to be a less invasive and aggressive method. A large number of clinical trials, as well as retrospective analysis of clinical and financial data, has shown that endometrial ablation allows for a lower morbidity and mortality rate and significantly lower procedure costs. Worldwide, endometrial ablation is increasingly being adopted by the gynecological community. Aim of the Work: to study the effect of bipolar radiofrequency ablation system on endometrial thickness and bleeding in patients with premenopausal bleeding. Patients and Methods: This study was conducted on: 30 women with premenopausal bleeding not responding to medical treatment. All subjects enrolled in the study were asked to give an informed written consent after explaining the nature, steps and aim of the study. The approval of Medical Ethics Committee was obtained. Results: the net results after treatment, the majority of the patients was improved $(83.3 \%), 19$ of them was complete recovery $(63.3 \%)$ while 6 cases $(20.0 \%)$ had minor bleeding, 4 cases $(13.3 \%)$ had bleeding less before treatment, while only one case had no change.Conclusion: Bipolar radiofrequency ablation performed under local anaesthetic in the postmenstrual phase is an effective and efficient method of treating the majority of women who wish conservative surgical treatment for heavy menstrual loss.
\end{abstract}

Keywords: bipolar radiofrequency ablation, NovaSure endometrial ablation, endometrial thickness, premenopausal bleeding.

\section{INTRODUCTION}

Menopause, also known as the climacteric, is the time in most women's lives when menstrual periods stop permanently, and they are no longer able to bear children. Menopause typically occurs between 49 and 52 years of age (2). Medical professionals often define menopause as having occurred when a woman has not had any vaginal bleeding for a year ${ }^{(\mathbf{1})}$. It may also be defined by a decrease in hormone production by the ovaries. In those who have had surgery to remove their uterus but still have ovaries, menopause may be viewed to have occurred at the time of the surgery or when their hormone levels fell ${ }^{(3)}$. Following the removal of the uterus, symptoms typically occur earlier, at an average of 45 years of age ${ }^{(4)}$.

Before menopause, a woman's periods typically become irregular, which means that periods may be longer or shorter in duration or be lighter or heavier in the amount of flow. During this time, women often experience hot flashes; these typically last from 30 seconds to ten minutes and may be associated with shivering, sweating, and reddening of the skin. Hot flashes often stop occurring after a year or two. Other symptoms may include vaginal dryness, trouble sleeping, and mood changes. The severity of symptoms varies between women. While menopause is often thought to be linked to an increase in heart disease, this primarily occurs due to increasing age and does not have a direct relationship with menopause. In some women, problems that were present like endometriosis or painful periods will improve after menopause ${ }^{(\mathbf{1})}$.

Menopause is usually a natural change. It can occur earlier in those who smoke tobacco. ${ }^{(5)}$. Other causes include surgery that removes both ovaries or some types of chemotherapy. At the physiological level, menopause happens because of a decrease in the ovaries' production of the hormones estrogen and progesterone. While typically not needed, a diagnosis of menopause can be confirmed by measuring hormone levels in the blood or urine ${ }^{(\mathbf{1})}$. Menopause is the opposite of menarche, the time when a girl's periods start ${ }^{(6)}$.

Specific treatment is not usually needed. Some symptoms, however, may be improved with treatment. With respect to hot flashes, avoiding smoking, caffeine, and alcohol is often recommended. Sleeping in a cool room and using a fan may help.The following medications may help: menopausal hormone therapy (MHT), clonidine, gabapentin, or selective serotonin reuptake inhibitors ${ }^{(1,7)}$. Exercise may help with sleeping problems. While MHT was once routinely prescribed, it is now only recommended in those with significant symptoms, as there are concerns about side effects. High-quality evidence for the effectiveness of alternative medicine has not been found. There is tentative evidence for phytoestrogens ${ }^{(8)}$. 
Hysterectomy is currently the leading treatment method for patients symptomatic for menorrhagia. Over 600,000 hysterectomies are performed every year in the USA alone. This surgical method of treatment was found to be efficacious, although it is associated with a number of well known and analyzed serious disadvantages. Hysterectomy has a relatively high morbidity and mortality rate, and direct and indirect costs associated with the procedure are also quite significant ${ }^{(9)}$.

Ablation of the endometrial lining of the uterus as an alternative to hysterectomy was found to be a less invasive and aggressive method. A large number of clinical trials, as well as retrospective analysis of clinical and financial data, has shown that endometrial ablation allows for a lower morbidity and mortality rate and significantly lower procedure costs. Worldwide, endometrial ablation is increasingly being adopted by the gynecological community ${ }^{(10)}$. The risks associated with the hysteroscopic approach are well known and include uterine wall perforation, intravasation of fluid distention media, hyponatremia, enceph alopathy and death. Technical challenges, the need for well-developed hand-eye-foot coordination, potential risks and other drawbacks of this treatment modality do not allow for a successful adoption of this procedure by the vast majority of gynecologists. In fact, only $15 \%$ of practicing gynecologists in the USA offer this treatment method ${ }^{(11)}$.

\section{Aim of the work}

The aim of the present work was to study the effect of bipolar radiofrequency ablation system on endometrial thickness and bleeding in patients with premenopausal bleeding.

\section{Patients and methods Patients}

This study was conducted on: 30 women with premenopausal bleeding not responding to medical treatment.

All subjects enrolled in the study were asked to give an informed written consent after explaining the nature, steps and aim of the study.

The approval of Medical Ethics Committee was obtained.

\section{Methods}

\section{All patients in this study were subjected to the following:}

1. Full history taking.

2. $\mathrm{CBC}$ and coagulation profile

3. Ultrasound examination to rule out uterine anomalies

4. Endometrial thickness more than $12 \mathrm{~mm}$

5. Endometrial biopsy to be done to rule out malignancy or hyperplasia.
6. Diagnostic hysteroscopy before ablation procedure to rule out any gross pathology.

7. Failed medical treatment to decrease the bleeding.

Inclusion criteria were:

- Age between 40-50 years

- Endometrial thickness $12 \mathrm{~mm}$ or more.

- Menorrhagia not responding to medical treatment.

- Endometrial biopsy reveals no malignancy or hyperplasia.

- Women who finished childbearing.

\section{Exclusion criteria were:}

- Women who still want to get pregnant.

- Patients with urinary or genital tract infection

- Patients with IUCD.

- Patients with suspects endometrial cancer

- Intrauterine lesions (polyp or fibroid)

- Endometrial thickness less than $12 \mathrm{~mm}$.

The methods used for identification and construction of the cohorts were previously published ${ }^{(12)}$.

\section{The Rochester Epidemiology Project}

Medical diagnoses and surgical interventions for each patient are routinely abstracted and coded according to the Hospital Adaptation of the International Classification of Diseases. ${ }^{(13)}$. These computerized indices allow the linkage of medical records from all providers and facilitate the evaluation of disease determinants and outcomes after surgical procedures. ${ }^{(14)}$.

\section{Interventions}

Patients were treated with bipolar RFA (NovaSure, Cytyc Surgical Products, Palo Alto, California), a method introduced in $2003{ }^{(15)}$. Before the procedure, all women had a Papanicolaou test, endometrial sampling, pelvic ultrasonography, and office hysteroscopy if structural uterine lesions were suspected. Only women with benign polyps or submucous leiomyomas not distorting the endometrial cavity or less than $2 \mathrm{~cm}$ in size were offered endometrial ablation. Removal was by dilation and curettage or ablation in situ.

\section{Baseline and Procedural Data}

Baseline data were obtained for each patient, including age, parity, body mass index, pattern of bleeding, presence of dysmenorrhea, uterine length, uterine position, presence of fibroids or polyps, endometrial thickness, and endometrial pathology. Previous operations, including cesarean births and tubal sterilization, were recorded. For procedural data, we noted the type of anesthesia used, total procedural time, 
balloon fluid volume and pressure for TBA, and the power setting for RFA.

\section{Follow-up and Measurement of Different Outcomes}

Treatment failure was defined as the need for another ablation procedure or hysterectomy at any point during follow-up, and time to treatment failure was the primary end point for the evaluation of outcome after GEA. Patients with treatment failure were identified by using the relevant International Classification of Diseases, Ninth Revision, Clinical Modification (ICD-9-CM) codes; records were reviewed individually to confirm failure and performance of re-ablation or hysterectomy. To avoid the confounding effect of menopause, the menstrual outcome of primary interest was amenorrhea; this was defined as the documented complete cessation of menstruation that began immediately after GEA and lasted for at least 12 months. Other secondary outcomes included postprocedural change in duration of bleeding, hemoglobin levels, and ferritin levels. Intraprocedural and postprocedural complications were recorded.

\section{RESULTS}

This study was conducted on 30 women with premenopausal bleeding not responding to medical treatment.

The data was collected, tabulated and analyzed as follow:

Table (1), show the distribution of the studied patients group regarding age and parity, the age ranged from $40-50$ years with a mean of $45.2 \pm 3.44$, regarding the parity the majority of the patients had 3 parity, while 10 cases had 1 para and 2 was two para.

Table (1): Distribution of the studied patients group regarding age and parity.

\begin{tabular}{|l|c|c|}
\hline & Number & Percent \\
\hline Age & 17 & 56.7 \\
$40-45$ & 13 & 43.3 \\
$45-50$ & \multicolumn{2}{|c|}{$40-50$} \\
\hline Range & \multicolumn{2}{|c|}{45.2} \\
Mean & \multicolumn{2}{|c}{} \\
S.D. & 10 & 33.3 \\
Parity & 6 & 20.0 \\
1 & 14 & 46.7 \\
2 & 14 \\
\hline
\end{tabular}

Table (2): Distribution of the studied patients group regarding body mass index, 12 patients $(40.0 \%)$ had normal weight, while 13 cases $43.3 \%$ was over weight, and 5 cases was obese, the body mass index was ranged from 21.0-31.8 with a mean of $26.24 \pm 3.54$.
Table (2): Distribution of the studied patients group regarding body mass index.

\begin{tabular}{|l|c|c|}
\hline & Number & Percent \\
\hline Body mass & 12 & \\
index & 13 & \\
Normal & 5 & 40.0 \\
weight & & 43.3 \\
Over weight & \multicolumn{2}{|c|}{$21.0-31.8$} \\
Obese & \multicolumn{2}{|c|}{26.24} \\
\hline Range & \multicolumn{2}{|c|}{3.54} \\
Mean & \multicolumn{2}{|c|}{} \\
S.D. & \\
\hline
\end{tabular}

Table (3), shows the distribution of the studied patients group regarding dysmenorrhea and previous cesarean delivery, only 4 cases (13.3\%) had dysmenorrhea, 12 patients had previous cesarean delivery.

Table (3): Distribution of the studied patients group regarding dysmenorrhea and previous cesarean delivery.

\begin{tabular}{|l|c|c|}
\hline & Number & Percent \\
\hline Dysmenorrhea & 4 & \\
Yes & 26 & 13.3 \\
No & 12 & \\
\hline Previous & \\
Cesarean & 18 & \\
delivery & & 40.0 \\
Yes & & 60.0 \\
No & \\
\hline
\end{tabular}

Table (4), show the distribution of the studied patients group regarding duration of bleeding (days), the majority of the patients had duration of bleeding less than 10 days while 7 cases (23.3\%) had duration more than 10 days, the duration of bleeding was ranged from 6-15 day with a mean of 8.10 \pm 2.17 .

Table (4): Distribution of the studied patients group regarding duration of bleeding (days).

\begin{tabular}{|l|c|c|}
\hline & Number & Percent \\
\hline Duration of & 23 & \\
bleeding & 23 & \\
$<10$ days & 7 & 76.7 \\
$>10$ days & & 23.3 \\
\hline Range & \multicolumn{2}{|c|}{$6-15$} \\
Mean & \multicolumn{2}{|c|}{8.10} \\
S.D. & \multicolumn{2}{|c|}{2.17} \\
\hline
\end{tabular}

Table (5), shows the comparison between pre and post endometrial thickness, before treatment the endometrial thickness was ranged from 12.2-18.6 with a mean of $15.74 \pm 1.89$ and decreased significantly after treatment to range 528.5 with a mean of $6.67 \pm 0.97$, there was a highly significant decrease in endometrial thickness after treatment $(\mathrm{p}<0.05)$. 
Table (5): Comparison between pre and post endometrial thickness

\begin{tabular}{|l|c|c|}
\hline & $\begin{array}{c}\text { Before } \\
\text { treatment }\end{array}$ & $\begin{array}{c}\text { After } \\
\text { treatment }\end{array}$ \\
\hline $\begin{array}{l}\text { Endometrial } \\
\text { thickness }\end{array}$ & & \\
Range & $12.2-18.6$ & $5.2-8.5$ \\
Mean & 15.84 & 6.67 \\
S.D. & 1.89 & 0.97 \\
\hline T & \multicolumn{2}{|c|}{8.16} \\
p & \multicolumn{2}{|c|}{$0.001^{*}$} \\
\hline
\end{tabular}

Table (6), show the comparison between pre and post Bleeding score, the bleeding score before treatment was ranged from 16-35 with a mean of $25.97 \pm 5.40$, after treatment the bleeding score was ranged from 7-12 with a mean of $9.60 \pm 1.87$, there was a significant decrease in bleeding score after treatment more than before treatment $(\mathrm{p}<0.05)$.

Table (6): Comparison between pre and post Bleeding score

\begin{tabular}{|l|c|c|}
\hline & $\begin{array}{c}\text { Before } \\
\text { treatment }\end{array}$ & $\begin{array}{c}\text { After } \\
\text { treatment }\end{array}$ \\
\hline Bleeding & & \\
score & & \\
Range & $16-35$ & $7-12$ \\
Mean & 25.97 & 9.60 \\
S.D. & 5.40 & 1.87 \\
\hline T & \multicolumn{2}{|c|}{6.25} \\
p & \multicolumn{2}{|c|}{$0.001 *$} \\
\hline
\end{tabular}

Table (7), shows the comparison between pre and post hemoglobin and hematocrit, the hemoglobin level before treatment was ranged from 6.5-11.2 with a mean of $8.58 \pm 1.31$ and increased significantly after treatment to be $3.77 \pm 0.31$, there was a significant increase in hemoglobin level after treatment ( $p<0.05)$. Regarding hematocrit before treatment the mean value was $31.56 \pm 4.82$, while after treatment the mean value of hematocrit was $42.28 \pm 6.32$, there was a significant increase in hematocrit after treatment $(\mathrm{p}<0.05)$.

Table (7): Comparison between pre and post $\mathrm{Hb}$ $\& \mathrm{Ht}$

\begin{tabular}{|l|c|c|c|}
\hline Hb & $\begin{array}{c}\text { Before } \\
\text { treatment }\end{array}$ & $\begin{array}{c}\text { After } \\
\text { treatment }\end{array}$ & $\begin{array}{c}\mathrm{T} \\
\mathrm{p}\end{array}$ \\
\hline Range & $6.5-11.2$ & $3.2-4.2$ & 7.25 \\
Mean & 8.58 & 3.77 & $0.001^{*}$ \\
S.D. & 1.31 & 0.31 & \\
\hline Ht & $23.92-$ & & \\
Range & 41.216 & $31.6-52.6$ & 8.16 \\
Mean & 31.56 & 42.28 & $0.001^{*}$ \\
S.D. & 4.82 & 6.32 & \\
\hline
\end{tabular}

Table (8), shows the comparison between pre and post RBCs and platelet, the mean RBCs before treatment was ranged from 3.2-4.2 with a mean of 3.770.31, and increased significantly after treatment to be $4.51 \pm 0.50$, there was a significant increase in RBCs after treatment ( $p<0.05)$. the platelet before treatment was ranged from 91-219 with a mean of $153.57 \pm 41.07$, there was no change after treatment in platelet count to be $140.37 \pm 33.52$ $(\mathrm{p}>0.05)$.

Table (8): Comparison between pre and post RBCs and platelet

\begin{tabular}{|l|c|c|c|}
\hline & $\begin{array}{c}\text { Before } \\
\text { treatment }\end{array}$ & $\begin{array}{c}\text { After } \\
\text { treatment }\end{array}$ & $\begin{array}{c}\mathrm{T} \\
\mathrm{p}\end{array}$ \\
\hline RBCs & & & \\
Range & $3.2-4.2$ & $3.2-5.3$ & 4.65 \\
Mean & 3.77 & 4.51 & $0.001^{*}$ \\
S.D. & 0.31 & 0.50 & \\
\hline Platelet & & & \\
Range & $91-219$ & $90-210$ & 0.081 \\
Mean & 153.57 & 140.37 & \\
S.D. & 41.07 & 33.52 & \\
\hline
\end{tabular}

Table (9), show the comparison between pre and post Prothrombin time (sec.), PTT (sec.) and Bleeding time (min.), the mean prothrombin time before treatment was $15.79 \pm 2.47$ and after treatment increase without any significant to be $16.70 \pm 2.82$, PTT before treatment was $62.39 \pm 13.81 \mathrm{sec}$, and after treatment was $68.53 \pm 9.20$, there was no significant difference between before and after treatment $(\mathrm{p}>0.05)$, bleeding time before treatment was $6.41 \pm 2.02$ and after treatment was $6.01 \pm 1.60 \mathrm{~min}$, no significant change in bleeding time after treatment ( $p>0.05)$.

Table (9): Comparison between pre and post Prothrombin time (sec.), PTT (sec.) and Bleeding time (min.)

\begin{tabular}{|l|c|c|c|}
\hline & $\begin{array}{c}\text { Before } \\
\text { treatment }\end{array}$ & $\begin{array}{c}\text { After } \\
\text { treatment }\end{array}$ & $\begin{array}{c}\mathrm{T} \\
\mathrm{p}\end{array}$ \\
\hline $\begin{array}{l}\text { Prothrombin } \\
\text { time (sec.) }\end{array}$ & & & \\
Range & $12-20.8$ & $12-21$ & 0.094 \\
Mean & 15.79 & 16.70 & \\
S.D. & 2.47 & 2.82 & \\
\hline PTT (sec.) & & & \\
Range & $42.2-85.8$ & $50.6-79.9$ & 0.064 \\
Mean & 62.39 & 68.53 & \\
S.D. & 13.81 & 9.20 & \\
\hline Bleeding & & & \\
time (min.) & & & \\
Range & $3.3-9.5$ & $3.5-9.5$ & 0.197 \\
Mean & 6.41 & 6.01 & \\
S.D. & 2.02 & 1.60 & \\
\hline
\end{tabular}

Table (10), show the distribution of the studied patients regarding the net results after 
treatment, the majority of the patients was improved $(83.3 \%), 19$ of them was complete recovery $(63.3 \%)$ while 6 cases $(20.0 \%)$ had minor bleeding, 4 cases $(13.3 \%)$ had bleeding less before treatment, while only one case had no change.

Table (10): Distribution of the studied patients regarding the net results after treatment

\begin{tabular}{|l|c|c|}
\hline & Number & Percent \\
\hline $\begin{array}{l}\text { Complete } \\
\text { recovery }\end{array}$ & 19 & 63.3 \\
\hline $\begin{array}{l}\text { Minor } \\
\text { bleeding }\end{array}$ & 6 & 20.0 \\
\hline $\begin{array}{l}\text { Bleeding less } \\
\text { before } \\
\text { treatment }\end{array}$ & 4 & 13.3 \\
\hline No change & 1 & 3.3 \\
\hline
\end{tabular}

Table (11), shows the distribution of the studied patients regarding their satisfaction after treatment, the majority of the patients was satisfied $(70.0 \%)$, while 5 cases was neutral feeling, 4 cases show unsatisfied.

Table (11): Distribution of the studied patients regarding their satisfaction after treatment.

\begin{tabular}{|l|c|c|}
\hline $\begin{array}{l}\text { Patients } \\
\text { satisfaction }\end{array}$ & Number & Percent \\
\hline $\begin{array}{l}\text { Very } \\
\text { satisfied }\end{array}$ & 6 & 20.0 \\
\hline Satisfied & 15 & 50.0 \\
\hline Neutral & 5 & 16.7 \\
\hline Unsatisfied & 3 & 10.0 \\
\hline $\begin{array}{l}\text { Very } \\
\text { unsatisfied }\end{array}$ & 1 & 3.3 \\
\hline
\end{tabular}

\section{DISCUSSION}

Menstrual disorders are common and account for $33 \%$ of referrals to gynecological practice ${ }^{(16)}$. The perceived loss of excessive blood during menstruation causes $5 \%$ of women aged 20 39 years to consult their gynecologist each year ${ }^{(17)}$. This problem has a significant impact on the health of the individual woman and on health care systems since its treatment is estimated to account for $1 \%$ of total health care costs. In over $50 \%$ of cases, no cause is found and the diagnosis of dysfunctional uterine bleeding (DUB) is made ${ }^{(\mathbf{1 6})}$. Endometrial ablation provides safe and effective treatment for women with DUB ${ }^{(18)}$.

The first-line treatment of heavy menstrual bleeding is medical treatment with either tranexam acid, oral contraceptives or levonorgestrelreleasing intrauterine device. If the treatment fails, the next option is either hysterectomy or endometrial ablation. Sometimes women do not want to have intrauterine device for personal reasons; in our long-term study only $37 \%$ of women had tried treatment of HMB with LNG-
IUS. Patients presenting with menorrhagia are typically 35 years or older, and many of them have gone through tubal ligation for birth control, and may thus be reluctant to use LNG-IUS to treat bleeding. Hysterectomy is a definitive solution, but it is a major operation with possible major complications. If a woman has a normal uterus which does not descend, the mode of hysterectomy is usually laparoscopic hysterectomy, which has a total complication rate of $15.4 \%$ and major complication rate of $4.3 \%{ }^{(19)}$. The number of hysterectomies performed because of menstrual disorders in Finland declined until 2007, after which it has been the same until 2011, between 600 and 800 per year. It is assumed that $1 / 3$ of hysterectomies performed for heavy menstrual bleeding are performed to women with normal uterus.

Endometrial ablation refers to a number of minimally invasive surgical procedures designed to treat AUB, which is defined as changes in frequency of menses, duration of flow, or amount of blood loss. EA consists of targeted destruction or removal of the endothelial surface of the uterine cavity in selected women who have no desire for future fertility. The procedure was designed to treat heavy menstrual bleeding refractory to medical therapy and not caused by structural uterine pathology. It is a less invasive alternative to hysterectomy ${ }^{(20)}$.

Second-generation endometrial ablation techniques have now been used for over 8 years and have demonstrated similar efficacy to firstgeneration endometrial ablation procedures ${ }^{(21)}$. The aim of this study is to compare the effectiveness and acceptability of two secondgeneration ablation procedures, the Cavaterm ${ }^{\mathrm{TM}}$ Thermal Ablation System (Cavaterm) and the NovaSure ${ }^{\mathrm{TM}}$ Impedance Controlled Endometrial Ablation System (NovaSure), in a double-blind, randomized trial.

The aim of the present work was to study the effect of bipolar radiofrequency ablation system on endometrial thickness and bleeding in patients with premenopausal bleeding

This study was conducted on: 30 women with premenopausal bleeding not responding to medical treatment.

In this study the patients age was ranged from $40-50$ years, the parity ranged from $1-3$, the body mass index was ranged from $21.0-31.8$ with a mean of $26.24 \pm 3.54,40.0 \%$ of the patients had previous cesarean delivery, the endometrial thickness before treatment was at least $12 \mathrm{~mm}$, and significantly decreased after treatment to be $6.67 \pm 0.97$. 
The literature regarding EA in patients with previous CS consists primarily of small retrospective cohorts studies. For resectoscopic EA, there are generally no restrictions following previous CS. However, caution should be exercised over the CS scar as myometrial thinning may predispose it to perforation or thermal injury. For a patient with previous transmural myomectomy, obtaining adequate visualization of the cavity using a pressure pump should allow for safe treatment. 8

In our study the bleeding score was significantly decreased after treatment to be $9.60 \pm 1.87$, from pre operative bleeding score (25.97 \pm 5.40$)$, this results was agreement with study carried by ${ }^{(22)}$.

The generalisability of the results are enhanced by the avoidance of entry criteria based on menstrual blood scores or predetermined uterine cavity regularity, while $69 \%$ of eligible patients referred for MEA would consider treatment under local anaesthetic ${ }^{(23)}$.

In our study the complete improved patients was 25 patients (83.3\%), while only one case failed, Treatment failure was defined as the need for another ablation procedure or hysterectomy at any point during follow-up, and time to treatment failure was the primary end point for the evaluation of outcome after GEA. Patients with treatment failure were identified by using the relevant International Classification of Diseases, Ninth Revision, Clinical Modification (ICD-9$\mathrm{CM}$ ) codes; records were reviewed individually to confirm failure and performance of re-ablation or hysterectomy. To avoid the confounding effect of menopause, the menstrual outcome of primary interest was amenorrhea; this was defined as the documented complete cessation of menstruation that began immediately after GEA and lasted for at least 12 months. Other secondary outcomes included postprocedural change in duration of bleeding, hemoglobin levels, and ferritin levels. Intraprocedural and postprocedural complications were recorded.

In other study they observed no significant differences in treatment failure rates between RFA and TBA (cumulative failure rate of $9 \%$ for RFA and $12 \%$ for TBA). The similar likelihood of treatment failure was unchanged after adjusting for known confounders of treatment failure, including age, parity, pretreatment dysmenorrhea, and history of tubal ligation. To date, only the RCT conducted by Abbott and colleagues ${ }^{(24)}$ has examined treatment failure in RFA and TBA; however, their trial was not statistically powered to compare treatment failure in the 2 groups, and they did not observe a significant differencein the rate of additional surgery within 12 months. In addition, at least 3 years of follow-up are needed for adequate evaluation of treatment failure after ablation.

In agreement with our study, in another study the overall "success" of the Cavaterm group was high, with $100 \%$ of women reporting eumenorrhea or better at 12-month follow-up. The amenorrhea rate in this group was significantly lower than in the NovaSure group, although the hypomenorrhea rate was significantly greater and the combined rates show no difference between the groups. The overall improvement in menstrual function is highly significant, and the difference between amenorrhea and spotting does not appear to affect either patient satisfaction, which is universally high for this procedure, or quality of life, which is improved.

It is essential that equipment failure be reported, as malfunction of the device or generator carries with it significant cost for disposable items and may require either retreatment at a later time or immediate treatment by an alternate method. In this study, equipment problems were encountered in $11 \%$ of the Cavaterm group and $8 \%$ of the NovaSure group. These problems did not seem to have a marked clinical effect in the Cavaterm group, although they contributed to poor outcomes for women in the NovaSure group. Other randomized trials using MEA and VestaDUB have reported a similar equipment failure rate of $3 \%$ and $4 \%$, respectively ${ }^{(25)}$.

The results of the previous study indicate that there is a significant improvement in menstrual status with both of these treatments. There is a significantly greater amenorrhea rate in the NovaSure group compared with the Cavaterm group. There is a significant improvement in quality of life for both techniques, with NovaSure providing better results compared with Cavaterm. Patient satisfaction is high with both techniques, with reintervention rates comparable to those reported in other published data. Equipment failure and problems must be considered as a factor for the secondgeneration endometrial ablation procedures, with an associated implication for clinical and costeffectiveness outcomes. These excellent short-term results need to be followed up in the longer term to ensure that the results are maintained ${ }^{(25)}$.

\section{CONCLUSION}

Bipolar radiofrequency ablation performed under local anaesthetic in the postmenstrual phase is an effective and efficient method of treating the majority of women who wish conservative surgical treatment for heavy menstrual loss. Treatment post-menses avoids the unpleasant side effects and significant costs of drug preparation. The technique is rapid, achieving both high satisfaction and 
acceptability rates, while also achieving menstrual outcomes and rates of further surgery unmatched by other endometrial ablative techniques. There are demonstrable lower cost to the health service and also the potential benefit of releasing valuable operating theatre time and personnel for other operations, which require these facilities.

\section{REFERENCES}

1. Eunice Kennedy Shriver National Institute of Child Health and Human Development (2015): Menopause: Overview. Available at: https://wikivisually.com/wiki/Menopause.

2. Takahashi TA; Johnson KM (2015): Menopause. The Medical clinics of North America, 99 (3): 521-34.

3. Leidy SL (2006): Menopause: a biocultural perspective . New Brunswick, N.J.: Rutgers University Press.

4. International position paper on women's health and menopause(2002): a comprehensive approach. DIANE Publishing.

5. Claudio N, Michelle $\mathbf{S}$ (2009): The menopausal transition: interface between gynecology and psychiatry

https://trove.nla.gov.au/version/45927241

6. James W (2017): Dynamics of Human Reproduction: Biology, Biometry. Demography Transaction Publishers.

7. Krause MS, Nakajima ST (2015): Hormonal and Nonhormonal Treatment of Vasomotor Symptoms. Obstetrics and Gynecology Clinics of North America, 42 (1): 163-179.

8. Oscar HF, Rajiv C, Jenna T, Trudy V, Setor K, Maryam K et al. (2016): Use of Plant-Based Therapies and Menopausal Symptoms. JAMA., 315 (23): 2554-63.

9. Dicker RC, Greenspan JR, Strauss LT et al. (1982): Complications of abdominal and vaginal hysterectomy among women of reproductive age in the United States. Am. J. Obstet. Gynecol., 144: 841-848.

10. Martyn $P$ and Allan B (1998): Long-term follow-up of endometrial ablation. J. Am. Assoc. Gynecol. Laparosc., 5(2): 115-118.

11. Hulka JF, Levy BS, Luciano AA, Parker WH, Phillips JM (1998): AAGL membership survey: practice profiles. J. Am. Assoc. Gynecol. Laparosc.,5: 93-96.

12. El-Nashar SA, Hopkins MR, Creedon DJ, Sauver JL, Weaver AL, McGree ME et al. (2009): Prediction of treatment outcomes after global endometrial ablation. Obstet Gynecol., 113(1):97-106.

13. Commission on Professional and Hospital Activities (1973): H-ICDA, hospital adaptation of ICDA. $2^{\text {nd }}$ ed. Commission on Professional and Hospital Activities; Ann Arbor (MI). Available at: https://www.ncbi.nlm.nih.gov/nlmcatalog/42700 3.

14. Melton LJ (1996): History of the Rochester Epidemiology Project. Mayo Clin Proc., 71(3):266-74.

15. Gallinat A and Nugent $W$ (2002): NovaSure impedance-controlled system for endometrial ablation. J Am Assoc Gynecol Laparosc., 9(3):283-9.

16. Coulter A, Noone A, Goldacre M (2009): General practitioners' referrals to specialist outpatient clinics. BMJ., 299:304 -8.

17. Vessey M, Villard-MacKintosh L, McPherson K (2012): The epidemiology of hysterectomy: findings of a large cohort study. Br J Obstet Gynaecol., 99:402-7.

18. Garry $\mathbf{R}$ (2002): Evidence and techniques in endometrial ablation: consensus. Gynaecol Endosc., 11:5-17.

19. Brummer TH, Jalkanen J, Fraser J, Heikkinen AM, Kauko M, Makinen J, Seppala T, Sjoberg J, Tomas E , Harkki P (2011): FINHYST, a prospective study of 5279 hysterectomies: complications and their risk factors. Hum Reprod., 26(7): 1741-1751.

20. Cooper K, Lee A, Chien P, Raja E, Timmaraju V, Bhattacharya S (2011): Outcomes following hysterectomy or endometrial ablation for heavy menstrual bleeding: retrospective analysis of hospital episode statistics in Scotland. BJOG., 118(10):1171-9.

21. Amso N, Stabinsky S, McFaul P, Blanc B, Pendley L, Neuwirth R (2009): Uterine thermal ablation therapy for the treatment of menorrhagia; the first 300 patients from a multi-centre study. $\mathrm{Br}$ J Obstet Gynaecol., 105:517-23.

22. Jack SA, Cooper KG, Seymour J (2005): A randomised controlled trial of microwave endometrial ablation without endometrial preparation in the outpatient setting: patient acceptability, treatment outcome and costs. International Journal of Obstetrics and Gynaecology, 112: 1109-1116.

23. Wallage S, Cooper KG, Graham WG, Parkin DE (2003): A randomised control trial comparing the acceptability of local anaesthesia plus or minus sedation and general anaesthesia for microwave endometrial ablation. Br J Obstet Gynaecol., 799807.

24. Abbott J, Hawe J, Hunter D, Garry R (2003): A double-blind randomized trial comparing the Cavaterm and the NovaSure endometrial ablation systems for the treatment of dysfunctional uterine bleeding. Fertil Steril., 80(1):203-8.

25. Corson S, Brill A, Brooks P, Cooper J, Indman $\mathbf{P}$, Liu J et al. (2007): One-year results of the Vesta system for endometrial ablation. J Am Assoc Gynecol Laparosc., 7:489 -97. 